\title{
O PASSEIO DE SCHREBER: UMA LEITURA A PARTIR DE DELEUZE E GUATTARI
}

\author{
THE SCHREBER RIDE: A READING FROM DELEUZE AND GUATTARI
}

\author{
Ana Karla Silva da Nóbrega ${ }^{1}$ \\ Patrícia Oliveira Lira ${ }^{2}$
}

Palavras-chave: Schreber; Deleuze; Guattari.

Paul Daniel Schreber (1842-1911), mais conhecido como o famoso "Dr. Schreber", foi um juiz alemão diagnosticado com demência paranoide que viveu períodos de internações clínicas psiquiátricas em diferentes momentos ao longo de sua vida, somando treze anos ao todo. Tomado pelos afectos da sua experiência, tornou-se escritor e resolveu narrar sua história no livro Memórias de um doente dos nervos publicado originalmente em 1903, onde podemos entrar em contato não apenas com a descrição de suas internações em instituições psiquiátricas, mas também, com todas as narrativas que bailam sua vida durante esses períodos. Devido à curiosidade que seu livro despertou em teóricos como Freud (1996) e Lacan (1998), ele acabou se tornando altamente conhecido dentro do meio acadêmico, mesmo nos dias atuais.

Dentre os que evocaram a figura de Schreber em sua obra, estão Deleuze e Guattari. Diferente de outros autores, a dupla não estava interessada em realizar uma análise ou diagnóstico de Schreber, em seu livro O Anti-Édipo: Capitalismo e Esquizofrenia (2010), o lugar de Schreber está associado com o "esquizo" que se apresenta desde o título da obra. Aqui, o esquizo não se refere àquele que possui uma entidade psiquiátrica, mas sim, aquele que escapa, vaza, cria o seu próprio código e "passeia" em uma fuga das estratificações dos códigos sociais:

O esquizo dispõe de modos de marcação que lhe são próprios, pois, primeiramente, dispõe de um código de registro particular que não coincide como o código social ou que só coincide com ele a fim de parodiá-lo (...) Dir-se-ia que o esquizofrênico passa de um código a outro, que ele embaralha todos os códigos, num deslizamento rápido, conforme as questões lhe apresentam, jamais dando seguidamente a mesma explicação, não invocando a mesma genealogia, não registrando da mesma maneira. (DELEUZE; GUATTARI, 2010, p. 29).

Por meio dessa perspectiva, tomando como referência a obra dos autores já mencionada, vamos propor uma leitura de Schreber, a partir da edição traduzida do seu livro publicado no Brasil em 1984, com o intuito de nos aproximarmos mais ao seu passeio do que ao seu diagnóstico.

Agora imagine um dito louco escrevendo um livro onde conta as memórias dos momentos em que sofreu uma crise de nervos, foi internado em uma instituição psiquiátrica e entrou em contato com os mais diversos milagres divinos, esse é o enredo que balança a leitura de Memórias de um doentes de nervos (1984) onde o Paul Schreber, ou simplesmente o Dr. Schreber, compartilha sua história. Sua escrita em formato de narrativa nos envolve numa série de acontecimentos que desafiam a ciência e a ordem do mundo. Por isso, quando iniciamos a leitura, quase que de maneira instintiva, o primeiro impulso é procurar os significados e descobrir o édipo, decifrar as fantasias, os delírios e as alucinações, destrinchar todos os conteúdos em busca de formular interpretações.

\footnotetext{
${ }^{1}$ Universidade de Pernambuco (UPE), PE, Brasil.

${ }^{2}$ Universidade de Pernambuco (UPE), PE, Brasil.
} 
Mas Schreber nos alerta o tempo todo que suas experiências "por serem sobrenaturais, são inconcebíveis ao homem". (SCHREBER, 1984, p. 144).

Um homem culto, criado severamente dentro de todos os códigos sociais e morais, fazendo coito consigo mesmo. Um homem que não era religioso escolhido por Deus para parir uma nova humanidade, tendo essa relação se tornado tão íntima que Schreber recebia suas visitas diariamente. É assim que ele mesmo se apresenta e, é por meio dessa contação que ele nos convida o tempo todo a entrar na sua história, sentindo as angústias e pulsações que percorrem em seu corpo. (SCHREBER, 1984).

Não se trata então de voltar à leitura para uma caça de significados escondidos nas entrelinhas, mas, sim, para a vida que suas memórias ganham quando ele narra suas experiências. É isso que ele joga na sua escrita o tempo todo. A angústia de não conseguir dormir por não ser capaz de parar de pensar. Os Homúnculos que andam em seu corpo e o fazem sentir os milhares de toques roçando em sua pele. Os seios que ganham formas. Os raios de Deus que saem do ânus e o poder de quem "de certo modo está justificado cagar sobre o mundo inteiro". (SCHREBER, 1984, p. 153-154). E ele narra de tal forma, que o leitor é provocado a sentir a angústia que sempre remete a dimensão do seu corpo:

O estranho no caso era que as almas ou nervos isolados, em certas condições e visando determinados objetivos, assumiam a forma de figuras humanas minúsculas (como foi observado, de apenas alguns milímetros) e como tais se imiscuíam em parte, no interior do corpo, em parte na sua superfície externa. Os que se ocupavam de abrir e fechar os olhos ficavam em cima dos olhos, nos supercílios e de lá puxavam as pálpebras para cima e para baixo, a seu belprazer, servindo-se de fios muito finos, semelhantes a fios de teia de aranha (...) Ficavam realmente passeando na minha cabeça, correndo curiosos por toda parte onde houvesse algo de novo para ver das destruições causadas na minha cabeça pelos milagres. (SCHREBER, 1984, p. 114).

O passeio do esquizo, ou o passeio do Schreber nesse caso, nos aponta o tempo todo o quanto o corpo entra em cena na sua experiência intensiva. Colocando em xeque a divisão mente/corpo, ele nos denuncia como recebe os fluxos intensivos incessantemente:

Cada palavra que me é dirigida ou falada nas minhas imediações, cada ação de uma pessoa, por menor que seja, que se associe a um certo ruído, por exemplo abrir o trinco da porta no meu corredor, mexer na fechadura da porta do meu quarto, a entrada de um enfermeiro, etc., é sentida por mim simultaneamente como uma pancada na cabeça, que provoca uma sensação dolorosa; a sensação de dor se manifesta na minha cabeça como um brusco puxão para trás, que produz uma sensação muito desagradável e que deve ser sempre acompanhada - pelo menos é esta a minha sensação - da extração de um pedaço da substância óssea do meu crânio. (SCHREBER, 1984, p. 141).

Definitivamente não é para todos, e ele afirma: “Qualquer pessoa que como eu não tivesse se tornado cada vez mais inventivo na utilização de meios de defesa adequados, se produziria uma impaciência nervosa que simplesmente a deixaria fora de si”. (SCHREBER, 1984, p. 152). Em paralelo ao sofrimento que ele vivia pela realização dos milagres que brincavam com o seu corpo, Schreber precisou ser inventivo ao ponto de criar estratégias para conseguir traçar uma relação de convivência com os raios divinos e suportar as dores e as volúpias que se manifestavam em seu corpo, como ele relata em vários momentos: 
Raramente me é possível persistir muito tempo na mesma ocupação; muito freqüentemente a ocorrência de dores de cabeça durante a leitura, o escrever, ou outra ocupação deste tipo, torna necessária uma mudança. Sob muitos aspectos, sou obrigado passar o meu tempo às voltas com passatempos insignificantes; do ponto de vista físico, isto me proporciona o maior bem-estar (além do tocar piano). Por isso, nos anos anteriores, tive muitas vezes que me ocupar de trabalhos mecânicos, como colagens, pinturas de figuras e coisas do gênero; do ponto de vista do bem-estar do corpo, são particularmente recomendáveis os trabalhos de tipo feminino, como costurar, tirar o pó, fazer a cama, lavar louça, e assim por diante. Ainda hoje, há dias em que, além de tocar piano, praticamente só posso me dedicar a essas pequenas coisas. (SCHREBER, 1984, p. 178).

É inegável que há uma grande quantidade de sofrimento: noites de insônia, efeitos colaterais e adaptação à rotina de medicamentos, a mudança nas dinâmicas das relações sociais, etc. É muita coisa para dar conta, e como disse Schreber, é necessária uma inventividade para lidar com tudo isso que surge e, é justamente para isso que Deleuze e Guattari vão chamar nossa atenção, para a potência do esquizo, apontando que, por exemplo, o próprio delírio seria uma qualificação do registro da produção desejante, e como tal, secundário dentro do processo, pois, o que importa aqui são as forças movidas:

Fala-se frequentemente das alucinações e do delírio; mas o dado alucinatório (eu vejo, eu escuto) e o dado delirante (eu penso...) pressupõem um Eu sinto mais profundo, que dá às alucinações seu objeto e ao delírio do pensamento seu conteúdo. Um "sinto que devenho mulher", "que devenho deus" etc., que não é delirante nem alucinatório, mas que vai projetar a alucinação ou interiorizar o delírio. Delírio e alucinação são segundos em relação à emoção verdadeiramente primária que, de início, só experimenta intensidades, devires, passagens. De onde vêm essas intensidades puras? Elas vêm das duas forças precedentes, repulsão e atração, e de sua oposição. (DELEUZE; GUATTARI, 2010, p. 34).

Assim, antes de passar por um filtro teórico ou médico está o fluxo intensivo que impulsiona o esquizo e o leva à produção. Quando nos voltamos para a biologia do delírio, ou, quando presos em interpretações enfiamos o édipo a todo custo, esvaziamos a potência e deixamos perdido o Eu que tanto se tenta resgatar pela via da "enunciação" (DELEUZE, 2004). Ora, o que mais teria o esquizo para falar, então, se tudo se reduz a uma mera disfunção neurológica, que serventia tem o seu discurso? O Eu-sinto se perde e a interpretação do mapa do sintoma enche de significados. São estratificações que cooptam o desejo e o colocam sob o funcionamento de uma lógica específica. $\mathrm{O}$ discurso, ou o Eu só é validado após o filtro interpretativo do analista ou da leitura sintomática do profissional da Saúde Mental. (DELEUZE, 2004).

Inspirados na ideia do sujeito nieztchiano Deleuze e Guattari trazem a metáfora de uma zona de intensidades formada por um círculo onde o centro não é a localização do sujeito, e sim, a máquina desejante. O sujeito está na borda porque é nesse movimento de passagem que ele pode sentir voluptas, o gozo de viver longe de uma fixidez:

(...) Não há o eu-Nietzsche, professor de filologia, que perde subitamente a razão, e que se identificaria com estranhas personagens; há o sujeitonieztchiano que passa por uma série de estados: todos os nomes da história sou eu... o sujeito se estende o contorno do círculo cujo centro o eu desertou. (DELEUZE; GUATTARI, 2010 p. 37). 
Ou seja, quebra-se o sentido do eu centralizado e da identidade como algo fixo. Partindo dessa perspectiva, os autores afirmam que desenhar a figura do esquizo de uma maneira cada vez mais cristalizada nos leva a um engessamento da sua identidade e afirmação da exclusão de sua potência:

Toda vez que se reconduz ao eu o problema do esquizofrênico, só resta apreciar uma suposta essência ou especificidade do esquizo, seja com amor ou piedade, seja para cuspi-la com nojo. Uma vez como eu dissociado, outra vez como eu cindido, e outra ainda, a mais faceira, como eu que não deixara de ser, que se achava especificamente aí, mas no seu mundo, e que se deixa encontrar por um psiquiatra astuto, um sobre-observador compreensivo, em suma, por um fenomenólogo. (DELEUZE; GUATTARI, 2010, p. 40).

Não há como fixar o esquizo porque o tempo todo ele está se movimentando. Produzindo, vazando, se reinventando. O próprio Schreber, foi de uma instituição à outra, de medicamento para medicamento, foi analisado, interpretado e transformado em caso, mas, ainda assim, deixou sua marca literária com uma escrita especialmente esquizo. Se o reduzimos ao homem que passou pelo delírio de tornar-se mulher, ou o homem que fazia amor com Deus, estaríamos reduzindo sua história a um pedaço que de fato chama a nossa atenção pelo sentido lógicointerpretativo, mas, não é só isso. O Schreber é àquele que sentiu o devir-mulher, o devirpássaro, o devir-dos raios divinos, e isso, e isso, e isso:

Nada é aqui representativo, tudo é vida e vivido: a emoção vivida dos seios não se assemelha aos seios, não os representa, assim como uma zona predestinada do ovo não se assemelha ao órgão que será induzido nela; apenas faixas de intensidade, potenciais, limiares e gradientes. Experiência dilacerante, demasiado emocionante, pela qual o esquizo é aquele que mais se aproxima da matéria, de um centro intenso e vivo da matéria. (DELEUZE; GUATTARI, 2010, p. 34).

O seu passeio foi nas mais diversas zonas intensivas. Multiplicidades, conexões, que o levaram desde a mais fortuita volúpia até a pior dor de cabeça que algum ser humano já sentiu. Sua escrita esquizo denunciou o tempo todo o quanto o corpo entra em cena e pede passagem. A potência do passeio do esquizo é capaz de produzir as mais diversas sensações mesmo naquele que está encarcerado dentro de uma cela, num chão duro e gelado. De fato, sua escrita nos leva para tão longe que em boa parte do texto muitas vezes nos esquecemos que se referem a momentos em que ele esteve internado em instituições. É isso. São infinitos passos que são dados mesmo no interior de uma cela ou quarto.

Ou seja, são dois modos de se ler Schreber. Ou se busca a decifração dos signos de sua narrativa louca na ânsia de localizar o binômio papai/mamãe e, assim, situar o esquema interpretativo de suas origens fundantes, ou se lança a passear na intensidade do último resíduo da desterritorialização: o corpo-sem-órgãos; percorrendo a processualidade de suas conexões que apontam seu modo de vida. Não importa se trata de uma recusa, trata-se da afirmação de si através da recusa. Schreber parece produzir aí um deslizamento esquizo no leitor de sua obra: da verdade de Schreber ao Schreber de verdade. (DELEUZE; GUATTARI, 2010).

\section{Referências}

DELEUZE, G. A Ilha Deserta e outros textos. São Paulo: Iluminuras, 2004. 
DELEUZE, G. GUATTARI, F. O Anti-Édipo: capitalismo e esquizofrenia. Tradução: Luiz B. L. Orlandi. São Paulo: Ed. 34, 2010. 560 p. (Coleção TRANS).

FREUD, S. Notas psicanalíticas sobre um relato autobiográfico de um caso de paranóia (dementia paranoides) (1911). In: FREUD, S. Obras Completas. Edição Standard Brasileira. v. XII. Rio de Janeiro: Imago, 1996. p. 07-54.

LACAN, J. De uma questão preliminar a todo tratamento possível da psicose (1957-1958). In: LACAN, J. Escritos. Tradução: Vera Ribeiro. Rio de Janeiro: Zahar, 1998. p. 537-590.

SCHREBER, D. P. Memórias de um doente dos nervos. Tradução: Marilene Carone. Rio de Janeiro: Edições Graal, 1984.

\section{Sobre as autoras}

Ana Karla Silva da Nóbrega. Bacharel em Psicologia pela Universidade de Pernambuco Campus Garanhuns.

E-mail: anakarla13@live.com.

Patrícia Oliveira Lira. Psicóloga e Bacharel em Psicologia pela Universidade Federal de Pernambuco, especializou-se em intervenção psicossocial à família no judiciário pela mesma universidade. Mestre em Psicologia Clínica pela Universidade Católica de Pernambuco e Doutora em Psicologia pela Université Paris13, França. Sua tese que versou sobre a violência familiar contra crianças na contemporaneidade lhe conferiu, em junho de 2011, o prêmio "Doctorat d'Honneur de l'Université Paris 13" e foi publicada pela editora Éditions Europeennes em abril de 2012. Ex-professora substituta da Universidade Federal de Pernambuco, com experiência na clínica de referencial psicanalítico, além de possuir experiencia de elaboração, execução e coordenação de projeto social e na supervisão de estágios curriculares em campo e na Universidade. É professora adjunta na Universidade de Pernambuco, onde atua na graduação e integra o corpo docente do mestrado profissional em Saúde Mental.

E-mail: patricia.lira@upe.br. 